What I said was, that it was " nearly two thirds less;" and I am quite satisfied with the anonymous writer's admission, that the attendants at the York dinner amounted to 70 . I have reason to believe they did not reach that number; but even if they did, the attendants at the Southampton dinner were not less than 170 .

'The consideration of any particular line of conduct, as 'vulgar,' 'brawling,' or 'bombastical,' I apprehend to be merely a matter of taste; and far be it from me to set up my opinion as the universal standard for trying gentlemanly demeanour or purity of style; I only hope that, in this free country, I may be permitted to form and express my own sentiments upon such subjects, on my own responsibility. With regard to intemperance in debate, men judge more according to definite rules; and as neither your Journal, nor the Worcester newspaper, afford the means of accurately judging of the conversation between Drs. Laycock and Hastings, I may be permitted to mention that I stayed away from the dinner at York, on the 5th inst., solely on account of Dr. Hastings' intemperate conduct; and that, upon that day, I accidentally met at dinner four gentlemen who acted similarly, upon the same grounds.

As your Journal is now the organ of the Provincial Medical Association, of which $I$ am proud to be a member, I trust you will see the justice of giving insertion to this letter in your next number; and I must also suggest, that neither a defence of Dr. Hastings, nor an attack upon any other member of the Association, should in future be conducted anonymously. Dr. Hastings, as secretary of the Association, is virtually responsible for the conduct of the acknowledged organ of the body ; and $I$ cannot think he is justified in making that organ the vehicle of an anonymous attack upon a brother member, even though he may think such to be necessary for his own defence.

$$
\text { I am truly yours, . }
$$

Dublin, Aug. 24, 1841.

\section{H. Macnsell.}

\section{TRANSACTIONS OF THE COLLEGE OF SURGEONS.}

TO THE EDITORS OF THE PROVINCIAL MEDICAL AND SURGICAL JOURNAL.

Royal College of Surgeons in London, September 6, 1841.

Gentlamen,-By direction of the President, I transmit to you the enclosed, and request the insertion thereof in your Journal.

Your obedient servant,

Edw. Belfour, Sec.

The Council proposing to publish, in the course of the ensuing year, a volume, to be entitled "Transactions of the Royal College of Surgeons in London," invite, from the members of the College and other scientific persons, communications relating to the improvement of anatomical and surgical science.

The subjects proposed to be included in this Publication are specified in the following extract from the Ordinances of the College :-

"The 'Transactions shall consist of-Original Communications on Surgical subjects-Collegial and Jacksonian Prize Dissertations, deemed o sufficient originality and merit-Original Memoirs on Human Anatomy - Original Memoirs on Comparative Anatomy-Anatomical Monographs of rare Animals, dissected in the Museum of the College-Explanations of, and Commentaries on, important Preparations in the Museum, with illustrative Plates-Statistical Reports from Hospitals."

It is requested that Papers intended for publication in this volume may be transmitted to the President, at the College, on or before the 1st of May 1842 .

\section{EXTRA-UTERINE CONCEPTION-GASTRO TOMY.}

M. Mathiev has communicated to the Academy of Medicine, Paris, an interesting case of this kind.

A woman, 38 years of age, became pregnant for the fourth time in the month of January 1835. At the ninth month labour pains set in, but the delivery made no progress. On examination the medical attendants discovered the existence of extra-uterine pregnancy. As a similar case in the neighbourhood had terminated, some short time before, in the discharge of the foetus through the abdominal parietes, they resolved on leaving the affair to nature. 'The pains, however, continued to increase, and the woman was reduced to such a state of despair that she applied to M. Mathieu, declaring that unless he operated she would destroy herself. As the abdomen contained a considerable quantity of fluid, M. Mathieu first tapped it, and was then enabled to distinguish the tumor formed by the fotus, with another tumor, as large as an ostrich's egg, behind the ensiform cartilage. After the lapse of two days, he incised the abdomen from the umbilicus to the pubis, in order to extract the fotus, and from the umbilicus to the ensiform cartilage, for the removal of the second tumor. The placenta adhered so firmly, that it was necessary to tear it away with the fingers, an operation which lasted seventeen minutes.

'The child was eighteen inches long, and weighed five pounds three ounces. 'The second tumor contained some hair, a matter analogous to brain, and a single bone, one inch long.

The patient was placed on milk diet; purged several times, and then took bark; chlorine injections were thrown into the abdomen, and it was found necessary to extract the pus from the abdominal cavity with an exhausting syringe. The patient, however, recovered in thirty-seven days, with a fistulous opening in the belly.-Exam. Med. No. 10.

\section{BOOKS RECEIVED.}

A Practical Treatise on the Efficacy of Mineral Waters on the Cure of Chronic Disease, \&c. By Sir A. M. Downie, M.D. Frankfort, 1841. 8\%o. lp. 219.

A Short Description of Kissingen, its Batlss and Mineral Waters. 'Iranslated from the German of Dr. Balling, by Sir A. M. Downie, M.D. Frankfort. 1841 .

Memoir on the Case of a Gentleman born Blind, \&c. (From the Philosoph. Trans.) By Augustus Franz, M.D. 